\title{
Paleoenvironmental considerations based on geochemistry and mineralogy of a Miocene lacustrine calcrete, southern Portugal
}

\author{
Ana Luísa Rodrigues ${ }^{1, *}$, Maria Isabel Dias ${ }^{1}$, Maria Isabel Prudêncio ${ }^{1}$, Fernando Rocha ${ }^{2,3}$, \\ Francisco Ruiz Muñoz ${ }^{1,4}$, Rosa Marques ${ }^{1}$, María Luz González-Regalado ${ }^{4}$, Dulce Russo ${ }^{1}$, \\ and Guilherme Cardoso ${ }^{1}$ \\ ${ }^{1}$ Centro de Ciências e Tecnologias Nucleares (C2TN), Instituto Superior Técnico, Universidade de \\ Lisboa, E.N. 10 (km 139.7), 2695-066 Bobadela LRS, Portugal \\ ${ }^{2}$ Departamento de Geociências, Universidade de Aveiro, Campus Universitário de Santiago, 3810- \\ 193 Aveiro, Portugal \\ ${ }^{3}$ GeoBioTec, Universidade de Aveiro, Campus Universitário de Santiago, 3810-193 Aveiro, Portugal. \\ ${ }^{4}$ Departamento de Ciencias de la Tierra, Universidad de Huelva, Avda. Tres de Marzo, s/n, 21007, \\ Huelva, Spain.
}

\begin{abstract}
A lacustrine carbonate facies has been investigated in Middle Miocene successions of the western side of the Moura-Marmelar basin, Southern Portugal in order to evaluate paleoenvironments in which carbonates formed, by using geochemistry and mineralogy. The studied formation corresponds to a recent unearthed section of a calcrete with an homogeneous carbonate facies comprising fine, whitish, and powdery material, and the only detected difference is a slightly hardness decrease towards the top, as well as an increase of weathered rock fragments (schist). The calcrete is calcium rich, even some magnesium enrichment was observed at the middle level, which is differentiated by a general depletion of all chemical elements, particularly REE, in both the bulk and clay-size fraction. Regarding the mineralogy, calcite prevails, and dolomite is only present in the middle level of the calcrete, together with a smectite enrichment, suggesting changes to more alkaline and low drainage, lacustrine and arid to semi-arid conditions.
\end{abstract}

\section{Introduction}

In Southern Portugal, particularly in the Moura basin, Paleogene and Neogene formations are predominantly carbonates developed in continental environments by pedogenic processes and/or under groundwater conditions, in lacustrine and palustrine settings. The Moura basin includes the most relevant calcrete formations from the region, mainly composed of Miocene to Pleistocene alluvial fan deposits related to tectonic activity, and preserved fluvial deposits associated with a Miocene $\mathrm{E}$ to $\mathrm{W}$ oriented paleodrainage. From the several depositional sequences identified in the region, for the calcretes from the Moura-Marmelar intermediate unit (Upper Miocene) there are

\footnotetext{
*Corresponding author: alsr@ctn.tecnico.ulisboa.pt
} 
only available general interpretations and descriptions of its different facies (highly indurated, nodular, and powdery) emphasising its enrichment in carbonate minerals (calcite and dolomite) and detrital materials [1]. Due to the topography of the region only after the Alqueva irrigation system construction in 2010, this calcrete became visible in the western sector of the MouraMarmelar unit with unearthing of a section of a thick powdery facies of the calcrete with around 2 $\mathrm{m}$ thick, at north of the Brinches village, in Cortes. In this work, a detailed study of the geochemistry and mineralogy of this calcrete is performed to better clarify its composition, development and paleoenvironmental conditions. Clay minerals reflect the lithology of the source rocks and the climate in the surrounding areas $[2,3]$. The use of the chemical and mineralogical composition of the clay fraction yield valuable palaeoenvironmental information and has proved to be a successful tool for palaeoenvironmental reconstruction in many different sedimentary basins (e.g., $[4,5]$. For the calcretes of Southern Portugal there is a lack of information related with those issues, so in this framework, this study intends to: (i) perform a novel and detailed assessment of their chemical composition, especially of trace elements distribution, and mineralogical composition, including both the bulk sample and clay-size fraction; and (ii) establish paleoenvironmental considerations. The mineralogical and geochemical data reported here intend to provide insights into the development of these type of calcrete deposits, and its usefulness for paleoenvironmental reconstruction in other regions of the world.

\section{Materials and Methods}

The Cortes calcrete has about $1.6 \mathrm{~m}$ height visible, covered by $0.3 \mathrm{~cm}$ of top soil, and field observations suggest that it is relatively homogeneous comprising fine, whitish, and powdery material, and the only observed difference is a slight decrease in hardness towards the top, as well as an increase of weathered rock fragments $(<5 \mathrm{~cm}$, schist). The topsoil above the calcrete also have weathered rock fragments and comprise fine, brownish and powdery material. Samples were collected from the bottom at the middle depth of each of the identified levels around $0.20 \mathrm{~m}, 1.20 \mathrm{~m}$, and at $1.75 \mathrm{~m}$, corresponding respectively to the representative samples $\mathrm{CTa}, \mathrm{CTb}$ and CTc. The bulk sample corresponds to the $<2 \mathrm{~mm}$ material separated by dry sieving. Although calcareous-rich samples are usually decalcified before particle-size analysis, key calcrete properties, such as the scavenging capacity of chemical elements by calcite, cannot be understood if the carbonate-fraction is removed [2]. It is also important to enhance that the bulk sample of the studied calcrete is in general powdery and of easy disaggregation. Therefore, no decarbonation procedure was performed in both bulk sample and clay-size fraction. After careful homogenisation, a portion of bulk sample was milled in agate mortars and prepared for chemical and mineralogical analyses. The silt-clay-size fraction $(<63 \mu \mathrm{m})$ was separated after dispersion of a bulk sample portion in distilled water by wet sieving. The clay-size fraction $(<2 \mu \mathrm{m})$ was separated by sedimentation according to Stokes' law. The mineralogical composition was determined by X-ray diffraction (XRD) using a Philips Pro-Analytical diffractometer with a $\mathrm{Cu}-\mathrm{K} \alpha$ source. Non-oriented aggregate powders were prepared for the bulk sample and scanned at $1^{\circ} 2 \theta / \mathrm{min}$ from 2 to $70^{\circ} 2 \theta$. Oriented specimens of the $<2 \mu \mathrm{m}$ fraction were prepared by air drying, ethylene glycol-solvated and heated at $550{ }^{\circ} \mathrm{C}$ for 2 hours [3]. Semi-quantitative analysis of mineral assemblage was undertaken measuring the principal peak areas with intensities correction, using the recommended weighting factors [4-8]. The chemical composition of the bulk sample was obtained by X-ray Fluorescence (XRF) and Instrumental Neutron Activation Analysis (INAA), and of the clay-size fraction by INAA. For XRF, powdered samples were mixed with Spectromelt A12 flux in 1:9 ratio, fused in a glassy pill and then analysed with a Philips PW 1410/00 spectrometer, using a CrK $\alpha$ radiation. The following major and minor elements were determined by XRF: $\mathrm{MgO}, \mathrm{Al}_{2} \mathrm{O}_{3}$, $\mathrm{SiO}_{2}, \mathrm{P}_{2} \mathrm{O}_{5}, \mathrm{SO}_{3}, \mathrm{CaO}, \mathrm{TiO}_{2}, \mathrm{~V}, \mathrm{Ni}, \mathrm{Cu}, \mathrm{Sr}, \mathrm{Y}, \mathrm{Mo}$ and I. For INAA approximately $200 \mathrm{mg}$ of each powdered dried sample and standards (GSD-9 and GSS-4 from the Institute of Geophysical and Geochemical Exploration [13]) were weighed in polyethylene vials and irradiated together using as neutron source the Portuguese Research Reactor (CTN/IST, Bobadela), with a neutron flux of $3.96 \times 10^{12} \mathrm{n} \mathrm{cm}^{-2} \mathrm{~s}^{-1}$ with $\varphi_{\mathrm{th}} / \varphi_{\mathrm{epi}}=96.8 ; \varphi_{\mathrm{th}} / \varphi_{\mathrm{fast}}=29.8$, 
during 6 hours in long irradiation and during 1.5 minutes in short irradiation [14-15]. INAA allowed the determination of the concentration of 30 chemical elements (major, minor and trace elements): $\mathrm{Na}_{2} \mathrm{O}, \mathrm{K}_{2} \mathrm{O}, \mathrm{Fe}_{2} \mathrm{O}_{3}$, Sc, Cr, Mn, Co, Zn, Ga, As, Br, Rb, Zr, Sb, Cs, Ba, La, $\mathrm{Ce}, \mathrm{Nd}, \mathrm{Sm}, \mathrm{Eu}, \mathrm{Tb}, \mathrm{Dy}, \mathrm{Yb}, \mathrm{Lu}, \mathrm{Hf}, \mathrm{Ta}, \mathrm{W}$, Th and U, with an accuracy $<5 \%$.

\section{Results and Discussion}

As expected, carbonates are the main minerals detected in the bulk sample, associated with various proportions of phyllosilicates and quartz, small amounts of feldspars and traces of hematite (Table 1). The deepest visible level of the calcrete ( $\mathrm{CTa}$ ) has the higher amounts of quartz and feldspars and the topsoil $(\mathrm{CTc})$ the highest proportion of phyllosilicates. The middle of the calcrete $(\mathrm{CTb})$ has the highest proportion of carbonates $(\sim 90 \%)$ and is the only one with dolomite. This might reflect a change to more alkaline conditions and higher $\mathrm{Mg} / \mathrm{Ca}$ ratios $(>10)$ [16]. Traces of hematite were detected in the middle and in the soil (CTb and CTc). The clay-size fraction of all samples comprises illite as main mineral, smectite and kaolin minerals in smaller proportions, as well as calcite in significant amounts. In the deepest visible level of the calcrete chlorite was detected, which can reflect a higher weathered degree of the detrital contribution from the surrounding schists, under oxidizing and acid conditions. Other evidences of the presence of inherited material from the parent rock (schists) is the high illite amounts in all samples, as well the micaceous minerals observed in the bulk sample. The middle sample has the higher smectite amounts, in accordance with an alkaline and $\mathrm{Mg}$ rich environment, that had also favoured the presence of dolomite in this level, pointing to a paleoenvironmental change to low drainage, lacustrine and arid to semi-arid conditions. Desiccation of the environment due to changing climatic conditions, and removal of $\mathrm{Ca}^{2+}$ from groundwaters by calcrete formation in surrounding areas, further concentrated $\mathrm{Mg}^{2+}$ and led to formation of dolomite-rich calcrete. A more detailed study of dolomite confirms these conditions. In a well-ordered dolomite crystal, $\mathrm{CaCO}_{3}$ layer and $\mathrm{MgCO}_{3}$ layer alternate regularly, which defines a well-ordered crystal structure, with the order being 1 . The intensity ratio of (015) and (110) dolomite diffraction peaks indicates approximately the degree of order (DO) in the crystal structure [17]: $\mathrm{DO}=I(015) / I(110)$. If the ratio is close to 1 the degree of order is high. This data together with the study of the molar content of $\mathrm{CaCO}_{3}$ $\left(\mathrm{N}_{\mathrm{CaCO} 3}=\mathrm{M}^{*} \mathrm{~d}(104)+\mathrm{B}\right)$ in the dolomite can also give a clue about its genesis [18]. Obtained results for the degree of order is of $0.435 ; \mathrm{CaCO}_{3}$ molar content is $82.88 \mathrm{~g} / \mathrm{molar}$. The lower ordered degree and calcium-rich composition indicate that the mineral was formed by replacing part of $\mathrm{Ca}^{2+}$ in calcium carbonate with $\mathrm{Mg}^{2+}$ and minor $\mathrm{Fe}^{2+}$ during precipitation.

Table 1. Mineralogical composition and semiquantification of the bulk sample and clay-size fraction of the materials collected in the lacustrine calcrete from Cortes-Brinches, Southern Portugal.

Notation: Phyl = phyllosilicates; Qtz = quartz; Fsp = feldspars; Cal =calcite; Dol = dolomite; Hem = hematite; Sme $=$ smectite; $\mathrm{Chl}=$ chlorite; $\mathrm{Ill}=$ illite; $\mathrm{Kln}=$ kaolin minerals; traces $-<2 \%$.

\begin{tabular}{|c|c|c|c|c|c|c|c|c|c|c|}
\hline & \multicolumn{5}{|c|}{ Bulk sample (\%) } & \multicolumn{3}{c|}{$\begin{array}{c}\text { Clay minerals in clay-size } \\
\text { fraction (\%) }\end{array}$} \\
\hline $\begin{array}{c}\text { Representati } \\
\text { ve Sample }\end{array}$ & Phyl & Qtz & Fsp & Cal & Dol & Hem & Sme & Chl & Ill & KIn \\
\hline CTc & 24 & 13 & 3 & 60 & - & traces & 22 & - & 64 & 14 \\
\hline CTb & 5 & 4 & 2 & 75 & 14 & traces & 38 & - & 44 & 18 \\
\hline CTa & 19 & 14 & 7 & 60 & - & - & 28 & 10 & 50 & 12 \\
\hline
\end{tabular}

In the bulk sample, the high carbonate content plays an important role in the chemical composition due to its "dilution effect" in chemical elements concentration, leading to a depletion of the majority of the studied elements, which is particularly evident in the middle level of the calcrete with the highest carbonate content. Exceptions were observed for the higher contents of 
$\mathrm{MgO}, \mathrm{CaO}, \mathrm{Sr}$, Mo and I in this calcrete level. The $\mathrm{Sr}$ is chemically similar to $\mathrm{Ca}$ so, a correlation with $\mathrm{CaO}$ was expected, as observed in Australian calcretes [19]. The deepest visible level of the calcrete has slightly higher contents of $\mathrm{K}_{2} \mathrm{O}, \mathrm{Rb}, \mathrm{Sn}$ and $\mathrm{Ba}$. The topsoil has slightly higher contents of $\mathrm{P}_{2} \mathrm{O}_{5}$ and $\mathrm{SO}_{3}$. Regarding the REE, low amounts were found for all levels, in opposition to the observed in calcretes from Tunisia where higher amounts of REE occurs, mainly associated with nodular and laminar-structured facies [20]. In the studied powdery calcrete, chiefly in the middle level $(\mathrm{CTb})$, a clear depletion of these chemical elements occurs, pointing to its fixation in the non-carbonated fraction. The fractionation values $\left(13<(\mathrm{La} / \mathrm{Yb})_{\mathrm{N}}<14 ; 3.8\right.$ $\left.<(\mathrm{La} / \mathrm{Sm})_{\mathrm{N}}<4.6\right)$, decrease from the bottom to the top of the Cortes calcrete profile and the Eu and Ce negative anomalies have no changes along the profile $\left(\mathrm{Eu} / \mathrm{Eu}^{*} \sim 0.6 ; \mathrm{Ce} / \mathrm{Ce} e^{*}<0.9\right)$. Steady negative anomalies observed along the profile point to the same order of magnitude of the Eu mobilization or leaching after the breakdown of primary minerals, during calcification processes. Considering the chemical composition of clay-size fraction, bottom level has the higher contents of all studied elements, with the exception of $\mathrm{Br}$. The middle level has the lower content of the majority of chemical elements studied, reflecting its higher carbonate content. Regarding the REE in the clay size fraction, the bottom is clearly enriched and has higher fractionating, and a lower $\mathrm{Ce}$ anomaly. Again, the middle level more carbonate rich, has lower REE, particularly the heavy REE (HREE). All samples have $\mathrm{Sr} / \mathrm{Ba}$ values lower than 1, discarding sedimentary environments with strong saline contributions of saline lakes or marine [17]. The lower $\mathrm{Sr} / \mathrm{Ba}$ was found for the bottom and top levels $(\sim 0.25)$, nevertheless the higher ratio was found for the medium level $(0.90)$, reinforcing a paleoenvironmental change at this level. Comparing the chemical composition of the clay-size fraction with the respective bulk sample (Fig. 1) a depletion in $\mathrm{K}_{2} \mathrm{O}$, REE, Ta and Th and an enrichment in $\mathrm{Mn}, \mathrm{As}, \mathrm{Br}, \mathrm{Sb}$ and $\mathrm{W}$ was observed at the bottom; the middle level only varies in the $\mathrm{Mn}$ and $\mathrm{U}$ behaviour that is depleted. In the topsoil a depletion of Mn, Co, As, Zr, Sb, REE, $\mathrm{Hf}$, Ta, Th and $\mathrm{U}$, and an enrichment of $\mathrm{K}_{2} \mathrm{O}$ and $\mathrm{W}$ was observed.

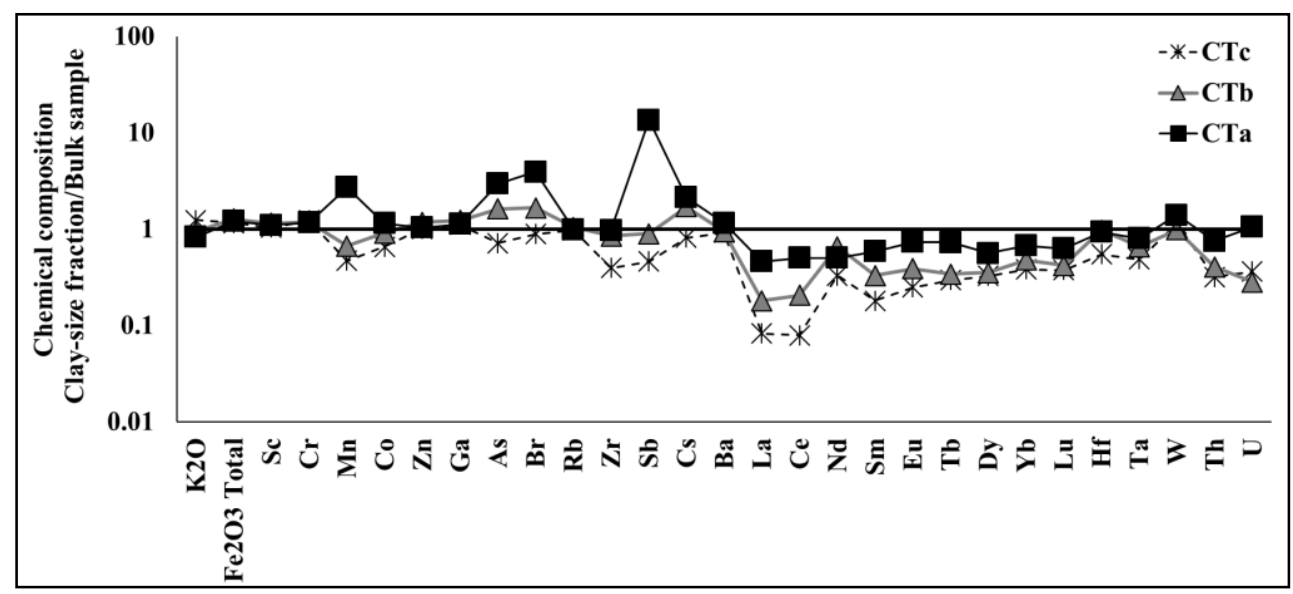

Fig. 1. Ratio between chemical composition of the clay-size fraction and the respective bulk sample for the materials from Cortes calcrete.

\section{Conclusions}

For the first time, a detailed assessment of the chemical composition, especially of trace elements distribution, and mineralogical composition of both the bulk sample and clay-size fraction, was performed for a Miocene lacustrine calcrete from Southern Portugal, also establishing paleoenvironmental considerations. As expected calcium prevails, confirming that this is not a $\mathrm{Mg}$ rich calcrete, even some enrichment of this element was observed at the middle level, that differs from the others due to a general depletion of all chemical 
elements, particularly REE, in both the bulk sample and clay-size fraction. Trace element contents are considered to be potential indicators of different carbonate facies, thus aiding the paleoenvironmental interpretation. However, discrimination on the basis of trace element contents appears to be difficult. More information is needed to ascertain their use as paleoenvironmental indicators. Regarding the mineralogical composition, also a change was observed at the middle level, the only one dolomite and smectite rich, pointing to a paleoenvironmental change to more alkaline with low drainage, lacustrine and arid to semiarid conditions. Therefore, the recent exposure of a relatively thick section of the calcrete from Cortes, is a possible evidence of a paleoenvironmental change during the Miocene in that region of Southern Portugal, as well as, a more comprehensive understanding of the development of calcrete deposits, and its usefulness for paleoenvironmental reconstruction.

The authors would like to thank the financial support by Fundação para a Ciência e Tecnologia (FCT, Portugal) through the projects UID/GEO/04035/2013 and UID/Multi/04349/2013.

\section{References}

1. J. Pais, The Paleogene and Neogene of Western Iberia (Portugal), Springer Berlin (2012)

2. H. Chamley, Clay Sedimentology, Springer-Verlag, New York, (1989)

3. C. M. Warshaw, and R. Roy, Geol Soc America Bull, 72, 455 (1961)

4. C.E. Weaver, Clays, Muds, and Shales, Developments in Sedimentology 44, Elsevier, Amsterdam (1989)

5. J.R. Hein, et al., Mar Environ Res, 56, 79-102 (2003)

6. D.C. Heroy, et al., Sediment Geol, 155, 343-359 (2003)

7. R. Kerry, et al., Geoderma, 152, 324-337 (2009)

8. L.G. Schultz, USGS Prof Paper 391 (1964)

9. J.M. Martin-Pozas, El analisis mineralógico cuantitativo de los filosilicatos de la arcilla por difracción de rayos $X$, U Granada, Spain (1968)

10. M.J. Trindade, et al., Appl Clay Sci, 42, 345-355 (2009)

11. R. Marques, et al., Clays Clay Miner, 59, 315-327 (2011)

12. M.J. Trindade, et al., Appl. Geochem, 44, 111-120 (2014)

13. K. Govindaraju, Geostand Newslett, 18, 1-158 (1994)

14. M.I. Dias, M.I. Prudencio, Archaeometry, 49, 383-393 (2007)

15. M.I. Prudêncio, et al., J Archaeol Sci, 36, 873-883 (2009)

16. M.I. Dias, et al., Appl. Clay Sci, 146, 334-342 (2017)

17. D.M. Deocampo, The Geochemistry of Continental Carbonates, Developments in Sedimentology 62 Elsevier, Amsterdam (2010)

18. X. Gao, et al., Geosci Front, 3, 669-680 (2012)

19. R.C. Lindholm, A Practical Approach to Sedimentology, Allen \& Unwin, London (1987)

20. K.G. McQueen, CRC LEME Open File Report 200 (2006) 